\title{
Voiding Dysfunction in Patients with Human T-lymphotropic Virus Type- 1-associated Myelopathy (HAM)
}

\author{
S. Komine, K. Yoshida, H. Yamashita, Z. Masaki \\ Division of Urology, Department of Surgery, Saga Medical School, Saga, fapan.
}

\begin{abstract}
Summary
Voiding dysfunction was evaluated in 16 of 17 patients with human T-lymphotropic virus type-1 associated myelopathy (HAM). Among 16 patients 11 had both frequency and difficulty in voiding and 12 had urge incontinence of urine. Sensation of vesical filling and voiding remained either intact or only slightly suppressed in all patients. Residual urine ranging from 50 to $320 \mathrm{ml}$ was observed in 14 patients. Urodynamic studies showed in every patient an overactive bladder with involuntary detrusor contraction. Only 2 patients had detrusor sphincter synergia, 6 patients had complete detrusor sphincter dyssynergia and 8 patients had incomplete detrusor sphincter dyssynergia. An overactive bladder associated with detrusor sphincter dyssynergia and less affected vesical sensation seems to be a characteristic urodynamic finding in HAM. These results combined with other neurological findings suggest that in patients with HAM lateral columns of the spinal cord between sacral and ponsmesencephalic micturition centre are mainly affected and that the posterior columns of the spinal cord are relatively less affected.
\end{abstract}

Key words: HTLV-1-associated myelopathy (HAM); Retrovirus; Voiding dysfunction; Urodynamic study.

In recent years HTLV-1 (human T-lymphotropic virus type-1) associated myelopathy, called HAM, has been recognised as a new clinical entity (Osame, 1986). Our institute, Saga Medical School is located in the middle part of Kyushu island which is the south-western part of Japan. In Kyushu island the incidence of adult T-cell leukaemia (ALT) is very high. There seems to be a high incidence of HAM because HTLV-1 is considered as a cause of ATL.

Over $90 \%$ of the patients with HAM had voiding dysfunctions and in some patients voiding disorders have been one of the first symptoms from the onset (Osame, 1987). Though most patients with HAM have voiding disorders, there yet have been few reports concerning its voiding dysfunction. We clinically 
evaluated voiding dysfunction in the patients with HAM with urodynamic studies.

\section{Material and methods}

From January 1986 to April 1988, 17 patients who had both a high concentration of serum anti HTLV-1 antibody titre and gradually progressing gait disturbance were diagnosed as patients with HAM by neurologists in our institution. The criteria of HAM includes (1) slowly progressive spastic paraparesis and voiding dysfunction, (2) high concentration of anti-HTLV-1 antigen titre in serum and cerebrospinal fluid (Osame et al., 1986). Their titre of serum anti HTLV-1 antibody ranged between 160 and 16500 times. Among 17 patients with HAM, 16 patients had voiding dysfunctions. These 16 patients were 6 males and 10 females, aged between 32 and 74 years with average of 53.9 years. The average age when their gait disturbance began was 39.9 years and that of voiding symptoms was 43.9 years. The interval between the onset of gait disturbance and that of the voiding symptoms was 4.0 years. Eleven cases had both frequency and difficulty with voiding of urine. Urge incontinence of urine occurred in 12 patients. Sensation of vesical filling and voiding remained either intact or only slightly suppressed in all patients. Residual urine ranging from 50 to $320 \mathrm{ml}$ was observed in 14 patients (Table I).

All the patients had a urodynamic study which, as reported previously, included measuring bladder pressure, urethral pressure, abdominal pressure and voiding cystourethrography (Iwatsubo, 1981 Komine, 1987). Some patients also had electromyography of the external urethral sphincter with a needle electrode simultaneously. A trilumen catheter of $\mathrm{Fr} 12$ size was transurethrally inserted into the bladder to measure both bladder pressure and sphincteric urethral pressure. Intrarectal pressure was monitored as abdominal pressure by a balloon catheter. The pressure that was obtained by subtracting abdominal pressure from bladder pressure was defined as detrusor pressure. Normal saline with contrast medium was infused into the bladder and the urethra at the rate of $10 \mathrm{ml} / \mathrm{min}$ via trilumen catheter which was fixed in the proper position under fluoroscopic monitoring.

Maximum detrusor pressure, bladder capacity at the beginning of the detrusor contraction and detrusor-sphincter correlation were considered as parameters of urodynamic study. Detrusor sphincter (dyssynergia (DSD) was classified into 2 types, complete and incomplete. In complete DSD sphincteric urethra always sustained high pressure during detrusor contraction (Fig. 1). While in incomplete DSD it decreased the pressure during detrusor contraction (Fig. 2).

\section{Results}

In the urodynamic study, all the patients had involuntary detrusor contraction with urgency and their maximum detrusor pressure ranged from 32 to $120 \mathrm{~cm}$ of water. The bladder capacity at the beginning of involuntary detrusor contraction was between 80 and $350 \mathrm{ml}$, average $230.6 \pm 80.2 \mathrm{ml}$ (Table II). 
Table I Clinical data, duration of the disease and symptoms of the patients

\begin{tabular}{|c|c|c|c|c|c|c|c|c|c|c|c|c|c|c|c|c|}
\hline Patients & 1 & 2 & 3 & 4 & 5 & 6 & 7 & 8 & 9 & 10 & 11 & 12 & 13 & 14 & 15 & 16 \\
\hline Sex & $\mathbf{M}$ & $F$ & $\mathbf{F}$ & $\mathbf{F}$ & $F$ & $\mathbf{M}$ & $\mathrm{F}$ & $M$ & $F$ & $M$ & $\mathbf{F}$ & M & $\mathbf{F}$ & $\mathbf{M}$ & $\mathbf{F}$ & $\mathbf{F}$ \\
\hline Age (years) & 60 & 74 & 41 & 33 & 63 & 32 & 61 & 59 & 65 & 34 & 42 & 64 & 68 & 53 & 63 & 51 \\
\hline Duration & & & & & & & & & & & & & & & & \\
\hline (years) & 10 & $?$ & 14 & 7 & 7 & 14 & 15 & 29 & 20 & 7 & 11 & 21 & 6 & 13 & 8 & 9 \\
\hline $\begin{array}{l}\text { Frequency } \\
\text { Urge }\end{array}$ & 0 & 0 & 0 & 0 & 0 & 0 & 0 & 0 & 0 & 0 & 0 & 0 & 0 & 0 & 0 & 0 \\
\hline incontinence & 0 & 0 & 0 & 0 & & 0 & & 0 & 0 & 0 & 0 & 0 & 0 & & 0 & \\
\hline $\begin{array}{l}\text { Difficulty } \\
\text { on voiding }\end{array}$ & & & 0 & 0 & 0 & 0 & 0 & 0 & & & & 0 & 0 & 0 & 0 & 0 \\
\hline $\begin{array}{l}\text { Residual } \\
\quad \text { urine (ml) }\end{array}$ & 0 & 50 & 310 & 55 & 100 & 120 & 150 & 155 & 80 & 0 & 290 & 230 & 200 & 320 & 150 & 300 \\
\hline
\end{tabular}

Table II Findings of urodynamic study

\begin{tabular}{|c|c|c|c|c|c|c|c|c|c|c|c|c|c|c|c|c|}
\hline Patients & 1 & 2 & 3 & 4 & 5 & 6 & 7 & 8 & 9 & 10 & 11 & 12 & 13 & 14 & 15 & 16 \\
\hline $\begin{array}{l}\text { Overactive } \\
\text { bladder }\end{array}$ & 0 & 0 & 0 & 0 & 0 & 0 & 0 & 0 & 0 & 0 & 0 & 0 & 0 & 0 & 0 & 0 \\
\hline $\begin{array}{l}\text { Maximum P.det } \\
(\mathrm{cm} H 20)\end{array}$ & 94 & 72 & 62 & 164 & 20 & 54 & 44 & 110 & 108 & 120 & 84 & 52 & 32 & 80 & 52 & 50 \\
\hline Synergia & 0 & 0 & & & & & & & & & & & & & & \\
\hline $\begin{array}{l}\text { Complete DSD } \\
\text { Incomplete }\end{array}$ & & & 0 & 0 & 0 & & 0 & & & & & 0 & & & 0 & \\
\hline DSD & & & & & & 0 & & 0 & 0 & 0 & 0 & & 0 & 0 & & 0 \\
\hline Bladder & & & 310 & & & & & & & & & & & & & \\
\hline capacity (ml) & 180 & 280 & & 160 & 110 & 80 & 300 & 200 & 210 & 150 & 350 & 230 & 280 & 350 & 200 & 300 \\
\hline
\end{tabular}

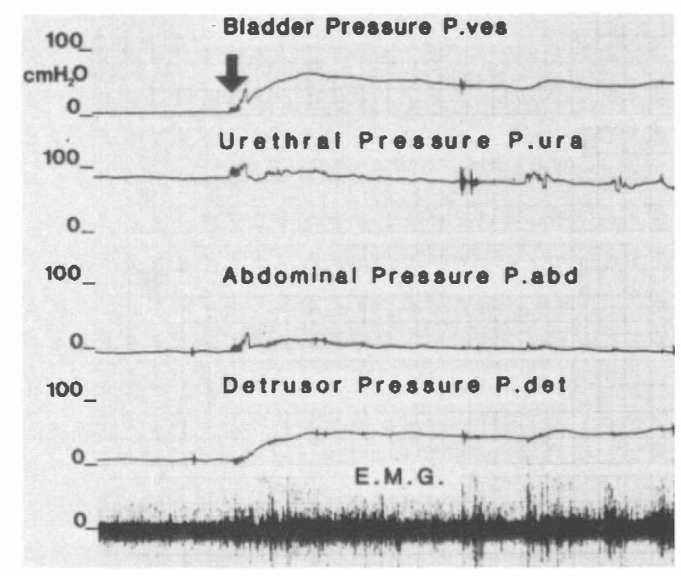

Figure 1 Urodynamic findings of the patient with complete DSD. Involuntary bladder contraction occurred (arrow) but urethral pressure did not decrease. Electromyography of the external urethral sphincter also showed DSD.

Detrusor-sphincter co-ordination was more or less distrubed in most patients. Only 2 patients had detrusor sphincter synergia and their residual urine was between 0 and $50 \mathrm{ml}$. Their voiding symptoms were both urinary frequency and urge incontinence without difficulty on voiding. Six patients had complete DSD and 8 patients had incomplete one (Table II). An overactive bladder and DSD were characteristic urodynamic findings of HAM. 


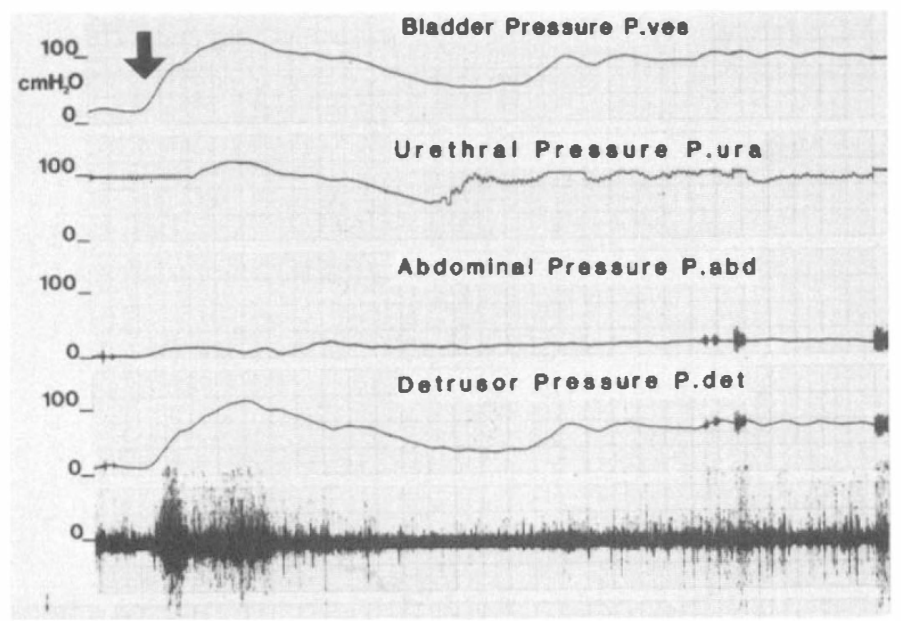

Figure 2 Urodynamic findings of the patient with incomplete DSD. Involuntary bladder contraction occurred (arrow) and urethral pressure slightly decreased after bladder contraction. Electromyography of the external urethral sphincter showed decrease of its voltage after bladder contraction.

\section{Discussion}

HTLV-1 and HTLV-3 belong to human retrovirus. HTLV-1 leads to adults T-cell leukaemia (ALT) and HTLV-3 which is called HIV (Human immunosuppressive virus) leads to acquired immunodeficiency syndrome (AIDS). Though only the patients with HAM have high concentration of anti-HTLV-1 antibody titre in serum and in cerebrospinal fluid, the pathophysiological mechanism of HAM is still unknown. Another myelopathy called tropical spastic paraparesis has been reported from India, Africa, Seychelles islands and Caribbean islands (Vernant et al., 1987). Tropical spastic paraparesis associated with increased concentration of serum anti HTLV-1 antibody titre may be considered identical with HAM, because the patients with tropical spastic paraparesis also have high incidence of increased concentration of serum anti HTLV-1 antibody titre and the main symptoms are common to those two types of myelopathies.

Our study showed a high incidence of voiding dysfunctions in patients with HAM and the main complaints of our patients were both frequency and difficulty of voiding. In an another report patients with HAM also had frequency and difficulty of voiding (Hiyoshi et al., 1987). Results of our urodynamic study revealed that overactive bladder led to urinary frequency and urge incontinence of urine and that DSD led to difficulty of voiding. Overactive bladder associated with sphincter dyssynergia and with less affected sensation seems to be characteristic urodynamic findings in HAM.

Detrusor motor neurons pass through the reticulospinal tract and those of the external urethral sphincter pass through the corticospinal tract. These tracts run through the lateral columns of the spinal cord (Bradley and Scott, 1978). An upper motor neuron lesion above the sacral micturition centre leads ta an overactive bladder. DSD may occur with the lesion between cauda and ponsmesencephalic micturition centre (Siroky, 1982). Ascending proprioceptive sensory impulses from detrusor and urethra pass through the posterior column of the 
spinal cord (Bradley and Scott, 1978). Considering these views together, our urodynamic findings and preservation of sensation of micturition suggest that in HAM the main lesions are lateral columns of the spinal cord between the sacral micturition centre and the pons-mesencephalic micturition centre and the posterior columns of spinal cord are less affected. These findings are similar to those of necropsy of the patient with HAM previously reported (Akizuki et al., 1987).

\section{Conclusions}

From the neurourological assessments of our 16 patients, the main characteristics of HAM seem to be as follows:

1. Voiding dysfunction appeared several years after the onset of gait disturbance.

2. Sensation of micturition is only slightly suppressed.

3. Urinary frequency and difficulty of voiding are due to detrusor hyperreflexia with sphincter dyssynergia.

These results combined with the other neurological findings suggest that the lateral columns of the spinal cord between scaral and pons-mesencephalic micturition centres are mainly affected and that the posterior columns of the spinal cord are less affected in HAM.

\section{Acknowledgement}

This report was announced in part at the 20th International Medical Society of Paraplegia Meeting in 1988, Perth, Western Australia.

\section{References}

Akizuki S, Nakazato Y, Higuchi Y, et al. 1987 Necropsy findings in HTLV-1 associated myelopathy. Lancet 1:156-157.

BRADLEY WE, SCOTt FB 1978 Physiology of the urinary bladder in Campbell's Urology, 4th edn, WB Saunders Company, Philadelphia, p. 87.

Hiyoshi T, Osame M, Moritoyo T 1987 Cystometric analysis of the urinary function of HTLV-1 associated myelopathy; A preliminary report. Acta Medica University of Kagoshima 29(1):19-27.

IWATSUBO E 1981 Bladder recovery in patients with traumatic cervical cord injury evaluated by synchronous cystosphincterometry with uroflowmetry. Fournal of Urology 126:503-508.

KOMINE S 1987 Recovery of bladder function in patients with spinal cord injury. Fapanese fournal of Urology 78(3):403-410.

OSAME M, UsuKu K, IzUMI I, et al. 1986 HTLV-1 associated myelopathy, a new clinical entity. Lancet 1:1031-1032.

Osame M, Igata A, Matsumoto M, et al. 1987 On the discovery of a new clinical entity: HAM. Advances in Neurological Sciences 31(5):727-745.

SIROKY MB, KRANE RJ 1982 Neurological aspects of DSD with ref erence to guarding reflex. fournal of Urology 127:953-957.

VERnANT JC, MARUS L, Gessain A, et al. 1987 Endemic tropical spastic paraparesis associated with human T-lymphotropic virus type 1: A clinical and seroepidemiological study of 25 cases. Annals of Neurology 21(2):123-130. 